\title{
Cyanide-bridged Trinuclear and Ethylenediamine-bridged One-dimensional Cobalt(III)-Manganese(II) Complexes: Synthesis, Crystal Structures and Magnetic Properties
}

\author{
Daopeng Zhang, Lifang Zhang, ${ }^{\dagger}$ Zengdian Zhao, and Zhonghai $\mathrm{Ni}^{\dagger}{ }^{*}$ \\ College of Chemical Engineering, Shandong University of Technology, Zibo 255049, PR China \\ ${ }^{\dagger}$ School of Chemical Engineering and Technology, China University of Mining and Technology, Xuzhou 221116, PR China \\ *E-mail: nizhonghai@cumt.edu.cn \\ Received June 2, 2011, Accepted June 13, 2011
}

\begin{abstract}
Two pyridinecarboxamide cobalt dicyanide building blocks and $\mathrm{Mn}(\mathrm{III})$ compounds have been employed to assemble cyanide-bridged heterometallic complexes, resulting in three trinuclear cyanide-bridged $\mathrm{Co}^{\mathrm{III}}-\mathrm{Mn}^{\mathrm{II}}$ complexes: $\left\{\left[\mathrm{Mn}(\mathrm{MeOH})_{4}\right]\left[\mathrm{Co}(\mathrm{bpb})(\mathrm{CN})_{2}\right]_{2}\right\} \cdot 2 \mathrm{MeOH} \cdot 2 \mathrm{H}_{2} \mathrm{O}(\mathbf{1}),\left\{\left[\mathrm{Mn}(\mathrm{MeOH})_{4}\right]\left[\mathrm{Co}(\mathrm{bpmb})(\mathrm{CN})_{2}\right]_{2}\right\} \cdot 2 \mathrm{MeOH} \cdot 2 \mathrm{H}_{2} \mathrm{O}$ (2) and $\left\{\left[\mathrm{Mn}(\mathrm{DMF})_{2}(\mathrm{en})_{2}\right]\left[\mathrm{Co}(\mathrm{bpb})(\mathrm{CN})_{2}\right]_{2}\right\} \cdot 2 \mathrm{DMF} \cdot \mathrm{H}_{2} \mathrm{O}(\mathbf{3})\left(\mathrm{bpb}^{2-}=1,2\right.$-bis(pyridine-2-carboxamido)benzenate, bpmb $^{2-}=1,2$-bis(pyridine-2-carboxamido)-4-methyl-benzenate, en $=$ ethylenediamine). Single crystal X-ray diffraction analysis shows their similar sandwich-like structures, in which the two cyanide-containing building blocks act as monodentate ligands through one of their two cyanide groups to coordinate the $\mathrm{Mn}$ (II) center. For complex 3, it was further linked into one-dimensional structure by ethylenediamine acting as bridges. Investigation of the magnetic properties of complex 3 reveals weak antiferromagnetic coupling between the neighboring $\mathrm{Mn}$ (II) centers through the bridging ethylenediamine molecule. A best-fit to the magnetic susceptibilities of complex 3 gave the magnetic coupling constant $\mathrm{J}=-0.073(2) \mathrm{cm}^{-1}$.
\end{abstract}

Key Words : Cyanide-bridged, Heterometallic complex, Crystal structure, Magnetic property

\section{Introduction}

As one of the most important magnetic systems, cyanidebridged complexes have received much attention in molecular magnetism field since their molecular topologies and magnetic coupling between neighboring metal centers through the cyanide bridge can be relatively easily controlled and predicted. During the past two decades, over twenty cyanide-containing precursors with or without peripheral organic ligands have been designed, synthesized, and employed in assembling into homo- or heterometallic cyanidebridged molecular magnetic materials with various structure types, including molecular clusters, 1D chains and 2D and 3D networks. ${ }^{1-11}$

Recently, a series of rigid dicyanide-containing building blocks based on pyridinecarboxamide ligands, in which these relatively large equatorial in-plane ligands can efficiently decrease the dimensions of the complex formed and weaken the intermolecular magnetic coupling, have been firstly employed to synthesize cyanide-bridged heterometallic complexes by our group. Based on these trans-dicyanidemetalate building blocks, many cyanide-bridged magnetic complexes with various of topologies, including binuclear and arc-like tetranuclear clusters, 1D chains and nanosized molecular wheels ${ }^{12-17}$ have been reported. In this paper, we investigated the reactions of trans-dicyanidecobalt(III) precursors with the manganese(III) compounds $\left[\mathrm{Mn}(\mathrm{acac})_{2}\right] \mathrm{Cl}$ and $[\mathrm{Mn}($ acacen $)] \mathrm{ClO}_{4}\left(\mathrm{acac}=\right.$ acetylaceto, acacen $=N, N^{\prime}-$ ethylene-bis(acetylacetonylideneaminate, Scheme 1) and

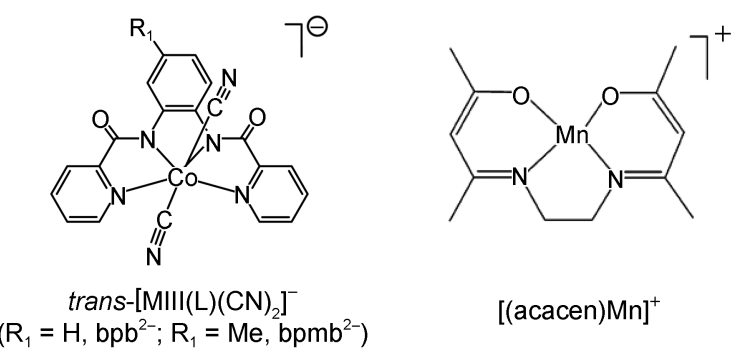

Scheme 1

obtained three trinuclear sandwich-like heterometallic cyanide-bridged $\mathrm{Co}(\mathrm{III})-\mathrm{Mn}$ (II) complexes, in which complex 3 was further linked into one dimensional structure by ethylenediamine molecule acting as bridges. Here, we present the synthesis, crystal structures, and magnetic properties of the three heterometallic cyanide-bridged $\mathrm{Co}$ (III)-Mn(II) complexes $\left\{\left[\mathrm{Mn}(\mathrm{MeOH})_{4}\right]\left[\mathrm{Co}(\mathrm{bpb})(\mathrm{CN})_{2}\right]_{2}\right\} \cdot 2 \mathrm{MeOH} \cdot 2 \mathrm{H}_{2} \mathrm{O}$ (1), $\left\{\left[\mathrm{Mn}(\mathrm{MeOH})_{4}\right]\left[\mathrm{Co}(\mathrm{bpmb})(\mathrm{CN})_{2}\right]_{2}\right\} \cdot 2 \mathrm{MeOH} \cdot 2 \mathrm{H}_{2} \mathrm{O}$ (2) and $\left\{\left[\mathrm{Mn}(\mathrm{DMF})_{2}(\mathrm{en})_{2}\right]\left[\mathrm{Co}(\mathrm{bpb})(\mathrm{CN})_{2}\right]_{2}\right\} \cdot 2 \mathrm{DMF} \cdot \mathrm{H}_{2} \mathrm{O} \quad$ (3) (bpb $^{2-}=1,2$-bis(pyridine-2-carboxamido)benzenate, $\mathrm{bpmb}^{2-}$ $=1,2$-bis(pyridine-2-carboxamido)-4-methyl-benzenate, en $=$ ethylenediamine).

\section{Experimental}

Elemental analyses of carbon, hydrogen, and nitrogen were carried out with an Elementary Vario El instrument. IR spectra of $\mathrm{KBr}$ pellets were recorded on a Magna-IR 750 
spectrophotometer in the $4000-400 \mathrm{~cm}^{-1}$ region. Variabletemperature magnetic susceptibility and field dependence magnetization measurements were performed on a Quantum Design MPMS SQUID magnetometer. The experimental susceptibilities were corrected for the diamagnetism of the constituent atoms (Pascal's tables).

All the reactions were carried out under air and all chemicals and solvents used were reagent grade without further purification. $\mathrm{K}\left[\mathrm{Co}^{\mathrm{III}}(\mathrm{bpb})(\mathrm{CN})_{2}\right]\left[\mathrm{bpb}^{2-}=1,2-\mathrm{bis}-\right.$ (pyridine-2-carboxamido)benzenate] and its analogue were synthesized as described in the literature. ${ }^{18}\left[\mathrm{Mn}(\mathrm{acac})_{2}\right] \mathrm{Cl}$ and $[\mathrm{Mn}$ (acacen) $] \mathrm{ClO}_{4}$ was available from previous works. ${ }^{19,20}$

Preparation of Complexes 1 and 2. To a solution of $\left[\mathrm{Mn}(\mathrm{acac})_{2}\right] \mathrm{Cl}(28.9 \mathrm{mg}, 0.1 \mathrm{mmol})$ in methanol $(10 \mathrm{~mL})$, $\mathrm{K}\left[\mathrm{Co}(\mathrm{bpb})(\mathrm{CN})_{2}\right](48.2 \mathrm{mg}, 0.10 \mathrm{mmol})$ or $\mathrm{K}\left[\mathrm{Co}(\mathrm{bpmb})(\mathrm{CN})_{2}\right]$ (49.6 mg, $0.10 \mathrm{mmol})$ dissolved in methanol/water (4:1, v:v) $(10 \mathrm{~mL})$ was added. The resulting mixture was filtered at once and the filtrate kept undisturbed at room temperature. After one week, brown-black block crystals were collected by filtration with a yield of $0.031 \mathrm{~g}, 54.6 \%$. Anal. Calcd. for $\mathrm{C}_{46} \mathrm{H}_{52} \mathrm{Co}_{2} \mathrm{MnN}_{12} \mathrm{O}_{12}$ : C, 48.56; H, 4.61; N, 14.77. Found: $\mathrm{C}$, 48.71; H, 4.70; N, 14.61. Main IR bands $\left(\mathrm{cm}^{-1}\right): 2162,2121$ $(\mathrm{s}, v \mathrm{C} \equiv \mathrm{N}), 1617,1623(\mathrm{vs}, \mathrm{vC}=\mathrm{N})$.

Complex 2: Yield 0.030g, 51.6\%. Anal. Calcd. for $\mathrm{C}_{48} \mathrm{H}_{56} \mathrm{Co}_{2} \mathrm{MnN}_{12} \mathrm{O}_{12}$ : C, 49.45; H, 4.84; N, 14.42. Found: $\mathrm{C}$, 49.52; H, 4.71; N, 14.53. Main IR bands $\left(\mathrm{cm}^{-1}\right): 2160,2120$ $(\mathrm{s}, v \mathrm{C} \equiv \mathrm{N}), 1617,1626$ (vs, vC $=\mathrm{N})$.

Preparation of Complex 3. $\mathrm{K}\left[\mathrm{Co}(\mathrm{bpb})(\mathrm{CN})_{2}\right](48.2 \mathrm{mg}$, $0.10 \mathrm{mmol})$ dissolved in methanol/water $(4: 1, \mathrm{v}: \mathrm{v})(10 \mathrm{~mL})$ was added to a solution of $[\mathrm{Mn}($ acacen $)] \mathrm{ClO}_{4}(37.7 \mathrm{mg}, 0.1$ $\mathrm{mmol})$ in methanol $(10 \mathrm{~mL})$, where upon dark-brown micro crystals were immediately precipitated. Single crystals suitable for X-ray diffraction were grown by slow diffusion from a DMF solution of the microcrystals, layered with ether, after about two weeks with a yield $0.031 \mathrm{~g}, 48.7 \%$. Anal. Calcd. for $\mathrm{C}_{54} \mathrm{H}_{62} \mathrm{Co}_{2} \mathrm{MnN}_{18} \mathrm{O}_{9}$ : C, 50.67; H, 4.88; N, 19.70. Found: C, 50.73; H, 4.95; N, 19.82. Main IR bands $\left(\mathrm{cm}^{-1}\right): 2159,2126(\mathrm{~s}, v \mathrm{C} \equiv \mathrm{N}), 1614,1627(\mathrm{vs}, \mathrm{vC}=\mathrm{N})$.

X-ray Data Collection and Structure Refinement. Single crystals of all the complexes with suitable dimensions for X-ray diffraction analyses were mounted on glass rods and the crystal data were collected on a Bruker SMART CCD diffractometer with a MoK $\alpha$ sealed tube $(\lambda=0.71073$ $\AA)$ at $293 \mathrm{~K}$, using $\omega$ scan mode. The structures were solved by direct methods and expanded using Fourier difference techniques with the SHELXTL-97 program package. The non-hydrogen atoms were refined anisotropically, while hydrogen atoms were introduced as fixed contributors. All of the non-hydrogen atoms, except the disordered ones, were refined with anisotropic displacement coefficients. For the disordered contents, the partially occupied atoms were refined isotropically. Hydrogen atoms were assigned isotropic displacement coefficients $\mathrm{U}(\mathrm{H})=1.2 \mathrm{U}(\mathrm{C})$ or $1.5 \mathrm{U}(\mathrm{C})$, and their coordinates were allowed to ride on their respective carbons using SHELXL97, except some of the $\mathrm{H}$ atoms of the solvent molecules. These $\mathrm{H}$ atoms were refined isotropically with fixed U values and the DFIX command was used to rationalize the bond parameter. CCDC 827303, 827304 and 827305 for complexes $\mathbf{1 - 3}$ contain the supplementary crystallographic data for this paper. These data can be obtained free of charge from the Cambridge Crystallographic Data Centre via www.ccdc.cam.ac.uk/data_request/ cif. Details of the crystal parameters, data collection, and refinement are summarized in Table 1.

\section{Results and Discussion}

Synthesis and General Characterization. In our recent works, ${ }^{12-17}$ pyridinecarboxamide trans-dicyanidemetalate building blocks have been successfully employed to construct cyanide-bridged heterometallic complexes with various structures by using $\mathrm{Mn}(\mathrm{III})$ compounds of salen type Schiff Base ligands, seven-coordinate macrocyclic manganese(II) compounds or polyaza-Ni(II) complexes as as-

Table 1. Crystallographic data for complexes 1-3

\begin{tabular}{lccc}
\hline & $\mathbf{1}$ & $\mathbf{2}$ & $\mathbf{3}$ \\
\hline chemical formula & $\mathrm{C}_{46} \mathrm{H}_{52} \mathrm{Co}_{2} \mathrm{Mn} \mathrm{N}_{12} \mathrm{O}_{12}$ & $\mathrm{C}_{48} \mathrm{H}_{56} \mathrm{Co}_{2} \mathrm{MnN}_{12} \mathrm{O}_{12}$ & $\mathrm{C}_{54} \mathrm{H}_{62} \mathrm{Co}_{2} \mathrm{MnN}_{18} \mathrm{O}_{9}$ \\
$F w$ & 1137.80 & 1165.85 & 1280.02 \\
crystal system & monoclinic & monoclinic & orthorhombic \\
Space group & $P 2(1) / n$ & $P 2(1) / n$ & $P b c n$ \\
$a / \AA$ & $8.6138(13)$ & $8.610(3)$ & $25.321(3)$ \\
$b / \AA$ & $11.7258(18)$ & $11.972(4)$ & $15.0247(16)$ \\
$c / \AA$ & $25.467(4)$ & $24.988(9)$ & $15.5350(17)$ \\
$\alpha /$ deg & 90 & 90 & 90 \\
$\beta /$ deg & $91.439(2)$ & 90.02 & 90 \\
$\gamma /$ deg & 90 & 90 & 90 \\
$V / \AA^{3}$ & $2571.5(7)$ & $2575.8(15)$ & $5910.1(11)$ \\
$Z$ & 2 & 2 & 4 \\
$F(000)$ & 1174 & 1206 & 2652 \\
$G O F$ & 1.059 & 1.013 & 1.015 \\
$R_{1}[I>2 s(I)]$ & 0.0349 & 0.0506 & 0.0672 \\
$w R_{2}$ (all data) & 0.0984 & 0.1209 & 0.2024 \\
\hline
\end{tabular}




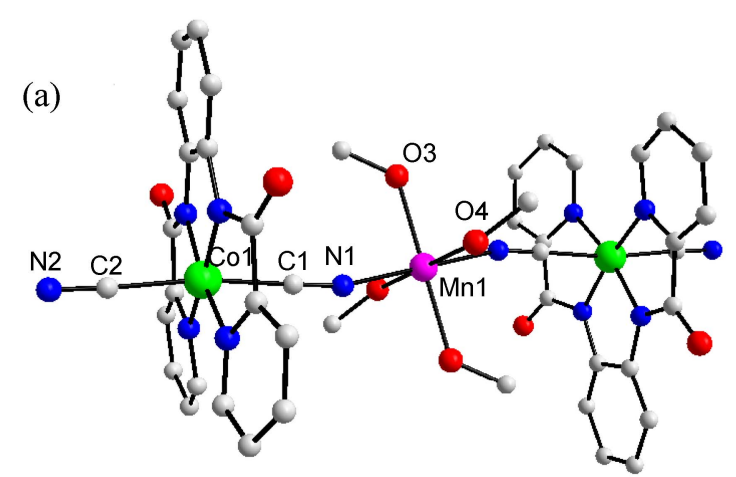

(b)
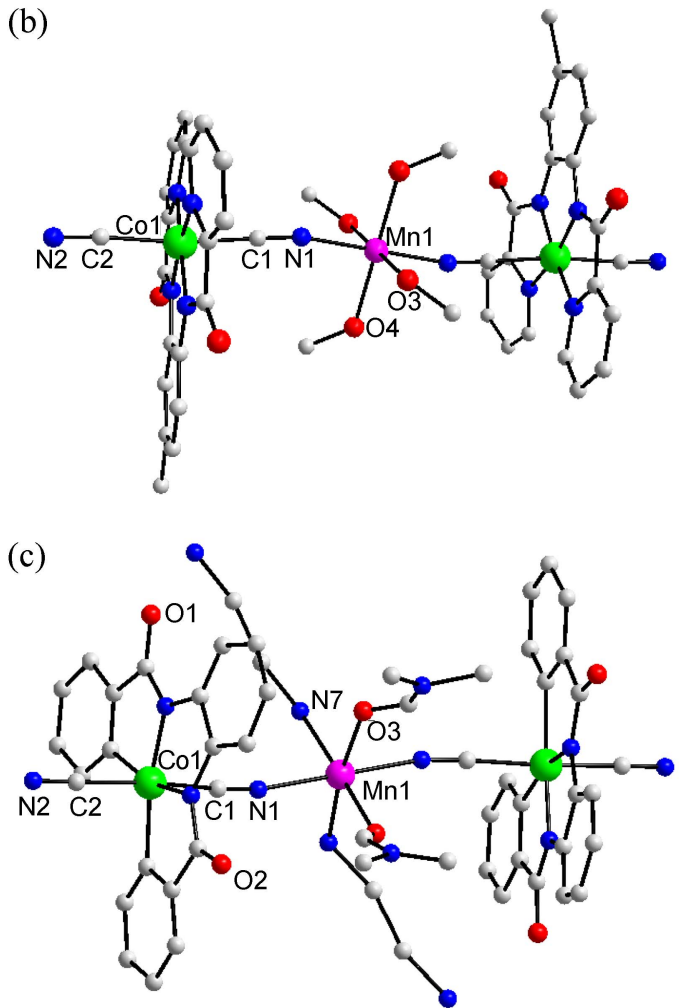

Figure 1. The trinuclear structure of complexes 1(a), 2(b), 3(c). The solvent molecules and all the $\mathrm{H}$ atoms have been omitted for clarity. sembling segments, indicating that these types of cyanide precursors are good candidates for the synthesis of lowdimensional cyanide-bridged complexes. In the present study, complexes 1-3 were obtained by the reactions of trans$\left[\mathrm{Co}(\mathrm{L})(\mathrm{CN})_{2}\right]^{-}$with the $\mathrm{Mn}(\mathrm{III})$ compounds $\left[\mathrm{Mn}(\mathrm{acac})_{2}\right] \mathrm{Cl}$ or $[\mathrm{Mn}($ acacen $)] \mathrm{ClO}_{4}$, in the form of stable heterometallic trinuclear cyanide-bridged $\mathrm{Co}(\mathrm{III})-\mathrm{Mn}(\mathrm{II})-\mathrm{Co}(\mathrm{III})$ systems. For complex 3, the initial acacen ligand was decomposed, therefore forming a cyanide and ethylenediamine mixbridged one dimensional structure.

In the IR spectra of complexes 1-3, two sharp peaks due to the cyanide stretching vibration were observed at about 2120 and $2160 \mathrm{~cm}^{-1}$, respectively, indicating the presence of both bridging and non-bridging cyanide ligands in these complexes. For complex 3, there exhibits two strong peaks at about 3420 and $3450 \mathrm{~cm}^{-1}$, which can be assigned the vibration of N-H bond.

Crystal Structures of Complexes 1-3. Some important structural parameters for complexes 1-3 are collected in Table 2. Their neutral trinuclear structures are shown in Figure 1. For complex 3, its ethylenediamine-bridged onediemnsional structure is given in Figure 2.

Table 2. Selected bond lengths $(\AA)$ and angles $\left({ }^{\circ}\right)$ for complexes 1-3

\begin{tabular}{llll}
\hline & \multicolumn{1}{c}{$\mathbf{1}$} & \multicolumn{1}{c}{$\mathbf{2}$} & $\mathbf{3}$ \\
\hline Mn1-N1 & $2.159(2)$ & $2.150(3)$ & $2.200(6)$ \\
Mn1-O3 & $2.212(2)$ & $2.192(3)$ & $2.193(6)$ \\
Mn1-O4/N7 & $2.2025(19)$ & $2.209(3)$ & $2.170(4)$ \\
Co1-C1 & $1.920(2)$ & $1.915(4)$ & $1.968(6)$ \\
Co 1-C2 & $1.926(2)$ & $1.917(4)$ & $1.983(6)$ \\
Co 1-N3 & $1.8976(19)$ & $1.891(3)$ & $1.891(4)$ \\
Co 1-N4 & $1.895(2)$ & $1.879(3)$ & $1.889(4)$ \\
Co 1-N5 & $1.982(2)$ & $1.962(3)$ & $1.990(4)$ \\
Co 1-N6 & $1.9770(19)$ & $1.959(3)$ & $2.000(4)$ \\
& & & \\
Mn1-N1-C1 & $167.2(2)$ & $167.5(3)$ & $167.5(5)$ \\
C1-Co1-C2 & $177.80(10)$ & $178.22(16)$ & $171.3(2)$ \\
Co1-C1-N1 & $179.1(2)$ & $178.7(4)$ & $175.6(5)$ \\
Co1-C2-N2 & $178.2(2)$ & $177.9(4)$ & $178.1(5)$ \\
\hline
\end{tabular}

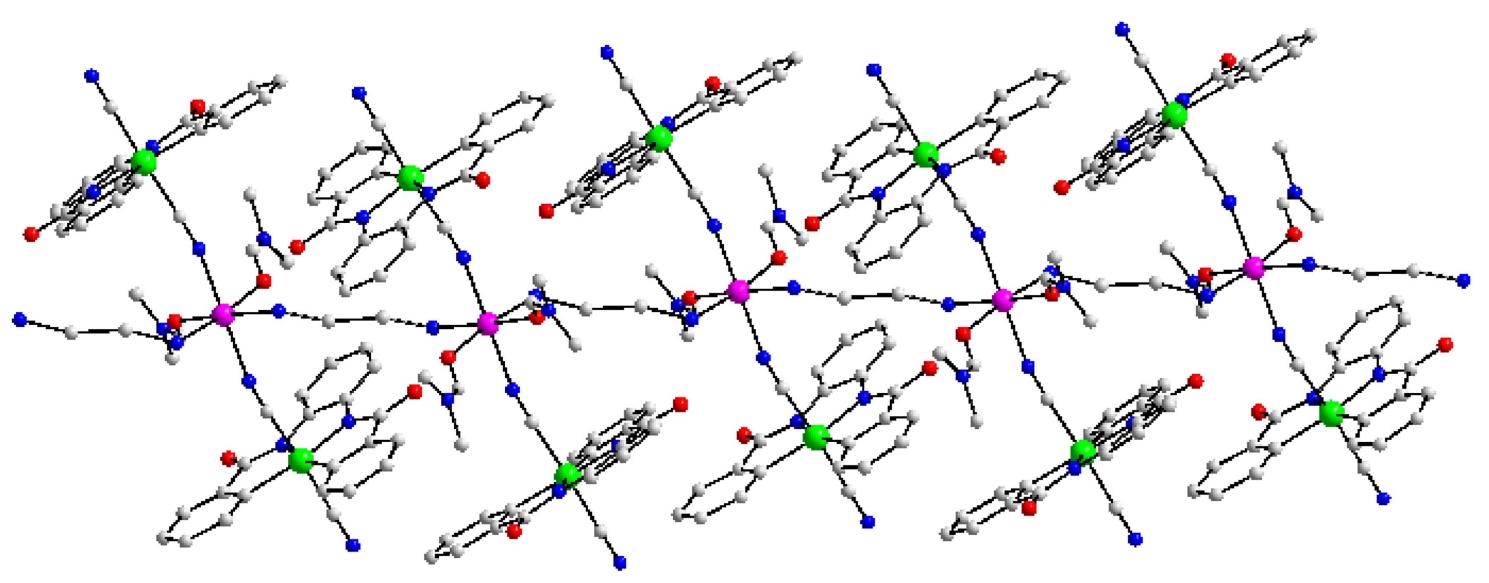

Figure 2. The one-dimensional structure for complex $\mathbf{3}$ formed by ethylenediamine. acting as bridges. The solvent molecules and all the $\mathrm{H}$ atoms have been omitted for clarity. 


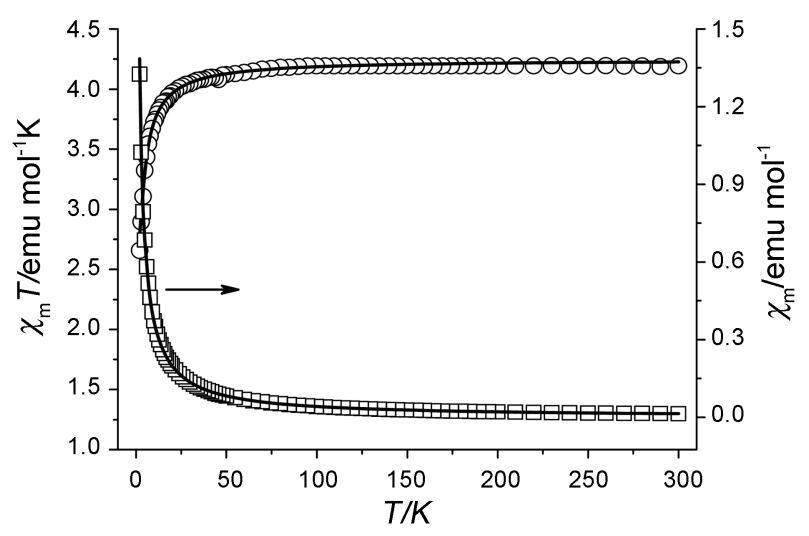

Figure 3. Temperature dependences of $\chi_{\mathrm{m}} T$ for complex 3 (the solid line represents the best fit based on the parameters discussed in the text).

As can be seen, complexes 1-3 possess similar trinuclear sandwich-like structures comprising of two trans$\left[\mathrm{Co}(\mathrm{L})(\mathrm{CN})_{2}\right]^{-}$units with the $\mathrm{Mn}(\mathrm{II})$ center in the middle. Complexes 1 and 2 crystallize in the monoclinic $P 2(1) / n$ group, while complex $\mathbf{3}$ crystallizes in the orthorhombic Pbcn group. In these three complexes, two $\left[\mathrm{Co}(\mathrm{L})(\mathrm{CN})_{2}\right]^{-}$ units, acting as a mono-dentate ligand through one of its its two cyanide groups, connect the central $\mathrm{Mn}(\mathrm{II})$. The Co atom is coordinated by four $\mathrm{N}$ atoms of the chelating ligands in the equatorial plane and two $\mathrm{C}$ atoms from the cyanide ligands in trans positions, forming a slightly distorted octahedral geometry. The Co- $\mathrm{N}$ bond lengths are in the very narrow range of 1.879(3)-1.8976(19) $\AA$ for these complexes and the $\mathrm{Co}-\mathrm{C}_{\text {cyanide }}$ bond lengths are distributed to the range of 1.915(4)-1.983(6) $\AA$. As listed in Table 2, the Co-C $\equiv \mathrm{N}$ bond angles in the realm of $175.6(5)-179.1(2)^{\circ}$ clearly indicate that the three atoms are in a very good linear configuration.

The coordination sphere for the $\mathrm{Mn}(\mathrm{II})$ atom in these complexes is also a octahedron, in which the four equatorial positions are occupied by four $\mathrm{O}$ atoms from methanol in complexes $\mathbf{1}$ and $\mathbf{2}$ and by two $\mathrm{O}$ atoms of coordinated DMF and two $\mathrm{N}$ atoms of two ethylenediamine ligands in complex $\mathbf{3}$, and the axial positions are occupied by the $\mathrm{N}$ atoms of the bridging cyanide groups. As shown in Table 2, the distances between the $\mathrm{Mn}$ atom and the $\mathrm{O}$ atoms of the solvent ligands, the $\mathrm{N}$ atom of ethylenediamine ligand are 2.212(2), 2.2025(19) $\AA$ (1), 2.192(3), 2.209(3) $\AA$ (2) and 2.193(6), $2.170(4) \AA$ (3), while the $\mathrm{Mn}-\mathrm{N}_{\text {cyanide }}$ bond lengths are 2.159(2), 2.150(3) and 2.200(6) $\AA$ for complexes 1, 2 and 3, respectively. The $\mathrm{C} 1 \equiv \mathrm{N} 1-\mathrm{Mn} 1$ angles in these three complexes are $167.2(2), 167.5(3)$ and $167.5(5)^{\circ}$, respectively, indicating that these three atoms deviate slightly from a linear configuration. The intramolecular $\mathrm{Mn}^{\mathrm{II}}-\mathrm{Mn}^{\mathrm{II}}$ separation through the bridging cyanide precursor is $10.38,10.36$ and $10.48 \AA$ for complexes $\mathbf{1}, \mathbf{2}$ and $\mathbf{3}$, respectively. Foe complex 3, the distance between the $\mathrm{Mn}(\mathrm{II})$ ions bridged by ethylenediamine is $8.17 \AA$.

Magnetic Properties of Complex 3. The magnetic properties for complex 3 have been investigated, and its mag- netic susceptibilities measured in the temperature range of 2$300 \mathrm{~K}$ at an applied field of 2000 Oe is given in Figure 3. The room temperature $\chi_{\mathrm{m}} T$ values is $4.20 \mathrm{emu} \mathrm{K} \mathrm{mol}{ }^{-1}$, slightly lower than the spin only value of $4.375 \mathrm{emu} \mathrm{K} \mathrm{mol}^{-1}$ for the isolated high spin $\mathrm{Mn}$ (II) $(S=5 / 2)$. With the temperature decreasing, the $\chi_{\mathrm{m}} T$ value remains almost constant from 300 to about $50 \mathrm{~K}$. After this, the $\chi_{\mathrm{m}} T$ value starts to decrease rapidly and reaches their lowest peak with the value of $2.65 \mathrm{emu} \mathrm{K} \mathrm{mol}{ }^{-1}$ at $2 \mathrm{~K}$. The magnetic susceptibility of complex $\mathbf{1}$ conforms well to Curie-Weiss law in a range of 2-300 $\mathrm{K}$ and gives the negative Weiss constant $\theta=$ $-1.13 \mathrm{~K}$ and Curie constant $C=4.22 \mathrm{emu} \mathrm{K} \mathrm{mol}{ }^{-1}$. These results primarily show the antiferromagnetic magnetic coupling between the two $\mathrm{Mn}$ (II) centers bridged by ethylenediamine molecule.

The magnetic data are analyzed by using the Hamiltonian: $\hat{H}=-2 \sum J \hat{\mathrm{S}}_{\mathrm{i}} \hat{\mathrm{S}}_{\mathrm{i}+1}$. The temperature dependence of the magnetic susceptibility is given by the equation: ${ }^{21}$

$$
\chi_{M}^{\text {chain }}=N g^{2} \beta^{2}\left\{S_{M n}\left(S_{M n}+1\right) / 3 k T\right\}\{(1+\mu) /(1-\mu)\}
$$

(Fisher's infinite chain model) with:

$$
\mu=\operatorname{coth}\left[J S_{M n}\left(S_{M n}+1\right) / K T\right]-\left[K T / J S_{M n}\left(S_{M n}+1\right)\right]
$$

The least-squares fit to the data leads to $J=-0.073(2) \mathrm{cm}^{-1}$, $\mathrm{g}=1.99(4), R=1.35 \times 10^{-5}$. The small $J$ value suggests the overall very weak magnetic coupling between the Mn(II) ions with a long separation.

\section{Conclusion}

In summary, two trans-dicyanidecobalt(III) precursors $\mathrm{K}\left[\mathrm{Co}(\mathrm{L})(\mathrm{CN})_{2}\right]$ were used as building blocks to assemble three trinuclear cyanide-bridged heterometallic $\mathrm{Co}(\mathrm{III})-$ $\mathrm{Mn}(\mathrm{II})$ complexes with sandwich-like structures. Due to the decomposition of the initial Schiff-Base ligand, one of them is further linked into one-dimensional structure by the coordinated ethylenediamine molecules acting as bridges. Investigation of the magnetic properties of complex 3 reveals weak antiferromagnetic interaction between the ethylenediamine-bridged Mn(II) centers.

Acknowledgments. This work was supported by the Natural Science Foundation of Shandong Province (ZR2011BM008) and the Science and Technology Project of High Education, Shandong Province (No. J11LB09).

\section{References}

1. (a) Lescouezec, R.; Toma, L. M.; Vaissermann, J.; Verdaguer, M.; Delgado, F. S.; F. Lloret, C. Ruiz-Perez.; Julve, M. Coord. Chem. Rev. 2005, 249, 2691. (b) Beltran, L. M. C.; Long, J. R. Acc. Chem. Res. 2005, 38, 325.

2. Miyasaka, H.; Saitoh, A.; Abe, S. Coord. Chem. Rev. 2007, 251, 2622.

3. Ohkoshi, S. I.; Ikeda, S.; Hozumi, T.; Kashiwagi, T.; Hashimoto, K. J. Am. Chem. Soc. 2006, 128, 5320.

4. Kaneko, W.; Kitagawa, S.; Ohba, M. J. Am. Chem. Soc. 2007, 129, 248.

5. Visinescu, D.; Desplanches, C.; Imaz, I.; Bahers, V.; Pradhan, R.; 
Villamena, F. A.; Guionneau, P.; Sutter, J. P. J. Am.Chem. Soc. 2006, 128, 10202.

6. Song, Y.; Zhang, P.; Ren, X. M.; Shen, X. F.; Li, Y. Z.; You, X. Z. J. Am. Chem. Soc. 2005, 127, 3708.

7. (a) Kim, J. I.; Yoo, H. S.; Koh, E. K.; Kim, H. C.; Hong, C. S. Inorg. Chem. 2007, 46, 8481. (b) Kim, J. I.; Yoo, H. S.; Koh, E. K.; Kim, H. C.; Hong, C. S. Inorg. Chem. 2007, 46, 10461. (c) Yoon, J. H.; Yoo, H. S.; Kim, H. C.; Yoon, S. W.; Suh, B. J.; Hong, C. S. Inorg. Chem. 2009, 48, 816. (d) Kim, J. I.; Kwak, H. Y.; Yoon, J. H.; Ryu, D. W.; Yoo, I. Y.; Yang, N.; Cho, B. K.; Park, J. G.; Lee, H.; Hong, C. S. Inorg. Chem. 2009, 48, 2956.

8. (a) Agustí, G.; Muñoz, M. C.; Real, J. A. Inorg. Chem. 2008, 47, 2552. (b) Agustí, G.; Muñoz, M. C.; Gaspar, A. B.; Real, J. A. Inorg. Chem. 2009, 48, 3371.

9. Yeung, W. F.; Lau, P. H.; Wang, X. Y.; Gao, S.; Szeto, L.; Wong, W. T. Inorg. Chem. 2006, 45, 6756.

10. Jiang, L.; Choi, H. J.; Feng, X. L.; Lu, T. B.; Long, J. R. Inorg. Chem. 2007, 46, 2181.

11. Bleuzen, A.; Marvaud, V.; Mathoniere, C.; Sieklucka, B.; Verdaguer, M. Inorg. Chem. 2009, 48, 3453. and references therein.
12. Ni, Z. H.; Zhang, L. F.; Tangoulis, V.; Wernsdorfer, W.; Cui, A. L.; Sato, O.; Kou, H. Z. Inorg. Chem. 2007, 46, 6029.

13. Ni, Z. H.; Kou, H. Z.; Zhang, L. F.; Ge, C.; Cui, A. L.; Wang, R. J.; Li, Y.; Sato, O. Angew. Chem., Int. Ed. 2005, 44, 7742.

14. Kou, H. Z.; Ni, Z. H.; Liu, C. M.; Zhang, D. Q.; Cui, A. L. New J. Chem. 2009, 33, 2296.

15. Ni, Z. H.; Kou, H. Z.; Zhao, Y. H.; Zheng, L.; Wang, R. J.; Cui, A. L.; Sato, O. Inorg. Chem. 2005, 44, 2050.

16. Zhang, D. P.; Wang, H. L.; Chen, Y. T.; Ni, Z. H.; Tian, L. J.; Jiang, J. Z. Inorg. Chem. 2009, 48, 5488.

17. Ni, Z. H.; Tao, J.; Wernsdorfer, W.; Cui, A. L.; Kou, H. Z. J. Chem. Soc., Dalton Trans. 2009, 2788.

18. Dutta, S. K.; Beckmann, U.; Bill, E.; Weyhermuller, T.; Wieghardt, K. Inorg. Chem. 2000, 39, 3355.

19. Stults, R. B.; Marianelli, R. S.; Day, V. W. Inorg. Chem. 1975, 14, 722.

20. Kou, H. Z.; Ni, Z. H.; Zhou, B. C.; Wang, R. J. Inorg. Chem. Commun. 2004, 7, 1150.

21. Kahn, O. Molecular Magnetism; VCH: New York, 1993; p 258. 